\title{
Asymmetric syntheses of daedalin A and quercinol and their tyrosinase inhibitory activity
}

Mitsuo Sekimoto, ${ }^{\mathrm{a}}$ Yasunao Hattori, ${ }^{\mathrm{b}}$ Keiji Morimura, ${ }^{\mathrm{c}}$ Mitsuru Hirota, ${ }^{\mathrm{d}}$ and Hidefumi Makabe ${ }^{\mathrm{a} *}$

${ }^{a}$ Sciences of Functional Foods, Graduate School of Agriculture, Shinshu University, 8304, Minami-minowa, Kami-ina, Nagano 399-4598, Japan

${ }^{\mathrm{b}}$ Department of Chemistry, Graduate School of Medicinal Science, Kyoto Prefectural University of Medicine, Kita-ku, Kyoto 603-8334, Japan

${ }^{c}$ Geol Cosmetics. Co., LTD, 111-1, Shinmura, Katsuragi, Nara 639-2121, Japan

${ }^{\mathrm{d}}$ Department of Bioscience and Biotechnology, Faculty of Agriculture, Shinshu University, 8304, Minamiminowa, Kami-ina, Nagano 399-4598, Japan

*Corresponding author. Tel. +81 26577 1630; fax +81 26577 1700, e-mail: makabeh@ shinshu-u.ac.jp

\begin{abstract}
Stereoselective syntheses of daedalin A and quercinol, an enantiomer of daedalin A, is described. The tyrosinase inhibitory activities of daedalin A and quercinol were examined. The activity of quercinol was weaker than that of daedalin A at high concentration.
\end{abstract}

Dermal hyper-pigmentation, caused by the accumulation of melanin, is initiated by oxidation of tyrosine by tyrosinase, a key enzyme of melanin biosynthesis. ${ }^{1}$ Tyrosinase inhibitors such as arbutin, kojic acid, ellagic acid, and rucinol have been used as pharmaceutical constituents of cosmetics in order to prevent hyper-pigmentation. In an effort to find new types of tyrosinase inhibitors, we have screened culture broths from mushroom mycelia for tyrosinase inhibitory activity, and found that the mycelial culture of Daedalia dickinsii showed significant activity. Based on the spectroscopic data, the bioactive compound was elucidated as (2R)-6-hydroxymethyl-2-methyl- $2 \mathrm{H}$ chromene, named daedalin A (1). ${ }^{2,3}$ We have synthesized racemic $\mathbf{1}$ and it showed weaker activity than $\mathbf{1}^{3}$ Quercinol (2), an enantiomer of daedalin A (1), was also isolated from the fungus of Daedalea quercina by Hertweck and co-workers. ${ }^{4}$ They reported that compound $\mathbf{2}$ showed anti-inflammatory activity. ${ }^{4}$ It is very difficult to obtain enough amount of daedalin A (1) and quercinol (2) for the biological study because the mycelia cultures of Daedalia dickinsii and/or Daedalea quercina are limited. Thus, syntheses of 1, 2, and their analogues are important for the biological study. Especially, synthesis of $\mathbf{2}$ is required because the tyrosinase inhibitory activity of $\mathbf{2}$ has not been reported yet. Herein, we wish to describe an asymmetric synthesis of $\mathbf{1}$ and $\mathbf{2}$ and their tyrosinase inhibitory activity (Figure 1). 

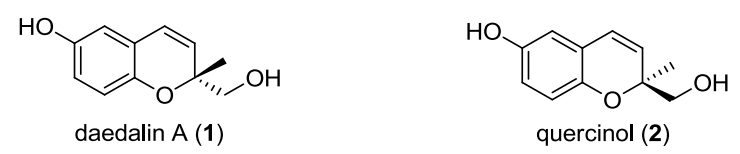

Figure 1. The structure of daedalin A (1) and quercinol (2).

The synthesis of daedalin A (1) is described as follows. Compound 4 was synthesized from 4-methoxyphenol and vinyloxirane using Pd-catalyzed $O$-alkylation using Kirschleger's method with modification. ${ }^{5}$ In this reaction Kirschleger used $1.5 \mathrm{~mol} \%$ of $\mathrm{Pd}\left(\mathrm{PPh}_{3}\right)_{4}$ at room temperature, however, sometimes the yield of desired product was low. Thus, we used $1 \mathrm{~mol} \%$ of $\mathrm{Pd}\left(\mathrm{PPh}_{3}\right)_{4}$ at $0^{\circ} \mathrm{C}$ to give desired product in high yield. Acetylation, Claisen rearrangement followed by Sharpless asymmetric epoxidation gave 9. ${ }^{5,6}$ Reduction with $\mathrm{LiAlH}_{4}$ followed by protecting 1,2-diol with 2,2-dimethoxypropane afforded 11. Oxidative demethylation of 11 with ceric ammonium nitrate (CAN) afforded 12 only in $21 \%$ yield with complex mixture. ${ }^{7}$ Probably the product was decomposed under acidic medium. Thus, we used silver (II) dipicolinate $\left\{\mathrm{Ag}(\mathrm{DPAH})_{2}\right\}$ in the presence of $\mathrm{AcONa}$ as an oxidant to give 12 in $96 \%$ yield. ${ }^{8}$ This method is useful for oxidizing acid sensitive substrate because oxidation can be proceeded under neutral medium. Transformation from 12 to 14 was achieved using Kirschleger's method. ${ }^{6}$ Protection of the hydroxy groups of $\mathbf{1 4}$ with $\mathrm{TBSCl}$ and imidazole afforded $\mathbf{1 5}$. Treatment of 15 with DDQ afforded 16. ${ }^{9}$ Finally, deprotection of the TBS ether of $\mathbf{1 6}$ with TBAF furnished daedalin A (1) in good yield. Recrystallization $\left(\mathrm{CHCl}_{3}\right)$ gave colourless solid whose melting point was $136-138{ }^{\circ} \mathrm{C}$. The specific rotation value of synthetic $\mathbf{1}$ was much higher than that of reported. All the spectral data of synthetic $\mathbf{1}$ were in good agreement with those of natural 1. (Scheme 1). ${ }^{2}$

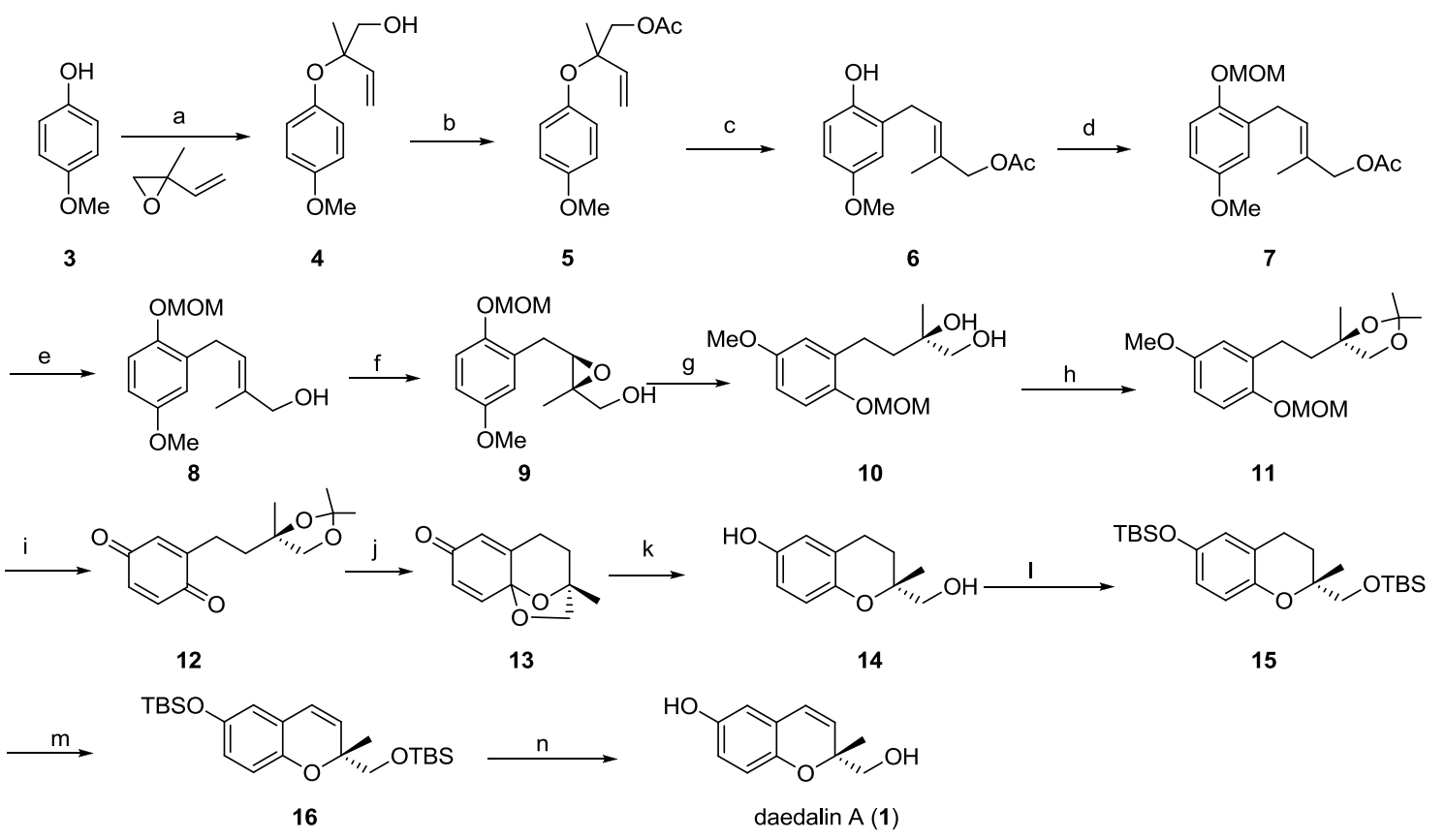


Scheme 1. Synthesis of daedalin A (1).

Reagents and conditions: (a) $0.5 \mathrm{~mol} \%$ of $\mathrm{Pd}\left(\mathrm{PPh}_{3}\right)_{4}, \mathrm{CH}_{2} \mathrm{Cl}_{2}, 0^{\circ} \mathrm{C}$ (93\%); (b) $\mathrm{Ac}_{2} \mathrm{O}, \mathrm{Et}_{3} \mathrm{~N}, \mathrm{DMAP}, \mathrm{AcOEt}$ (quant.). (c) $\mathrm{HCl}$ (gas), $\mathrm{CH}_{2} \mathrm{Cl}_{2}$ (99\%). (d) $\mathrm{MOMCl}, i$-Pr $2 \mathrm{NEt}, \mathrm{CH}_{2} \mathrm{Cl}_{2}$ (99\%). (e) $\mathrm{K}_{2} \mathrm{CO}_{3}, \mathrm{MeOH}$ (quant.). (f) TBHP, Ti(O-iPr) $)_{4}$ L-(+)-DET, $\mathrm{CH}_{2} \mathrm{Cl}_{2}$ (78\%). (g) $\mathrm{LiAlH}_{4}$, diethyl ether, (88\%). (h) DMP, $p$-TsOH (quant.). (i) $\mathrm{Ag}(\mathrm{DPAH})_{2}, \mathrm{AcONa}, \mathrm{MeCN}-\mathrm{H}_{2} \mathrm{O}(96 \%)$. (j) $1 \mathrm{~N} \mathrm{HCl}, \mathrm{MeOH}(90 \%)$. (k) Red-Al, THF, $-78{ }^{\circ} \mathrm{C}$ (92\%). (l) TBSCl, imidazole, DMF (quant.). (m) DDQ, benzene (81\%). (n) TBAF, THF (95\%).

Synthesis of quercinol (2) was achieved as the same procedure of daedalin A (1) except that D-(-)-DET was used in the Sharpless epoxidation. The melting point and specific rotation values were higher than those reported. All the spectral data of synthetic $\mathbf{2}$ were in good agreement with those of natural 2 (Scheme 2). ${ }^{4}$

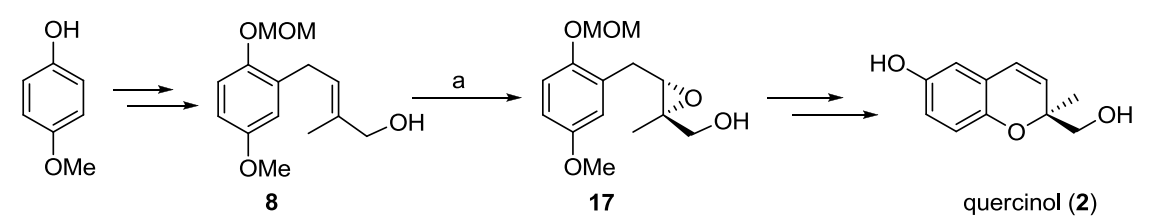

Scheme 2. Synthesis of quercinol (2).

Reagent and condition: (a) TBHP, $\mathrm{Ti}(\mathrm{O}-i \mathrm{Pr})_{4}$, D-(-)-DET, $\mathrm{CH}_{2} \mathrm{Cl}_{2}(89 \%)$.

The HPLC analysis of the synthetic 1 and $\mathbf{2}$ using chiral column showed more than 99\% ee, respectively.

The tyrosinase inhibitory activities of $\mathbf{1}$ and $\mathbf{2}$ were examined. Interestingly, the tyrosinase inhibitory activity of $\mathbf{2}$ was weaker than that of 1 at higher concentration $(400 \mu \mathrm{M})$. This result suggested that the mechanism of action of quercinol (2), which has an opposite stereochemistry at C-2 position, might be different from that of daedalin (1) in the tyrosinase inhibitory activity (Table 1$)^{3}$

Table 1. Tyrosinase inhibitory activities of 1,2 and \pm daedalin $A$.

\begin{tabular}{lcccc}
\hline \multicolumn{5}{c}{ Inhibition \pm SD $(\%)^{\mathrm{a}}$} \\
\hline compound & $100 \mu \mathrm{M}$ & $200 \mu \mathrm{M}$ & $400 \mu \mathrm{M}$ & $\mathrm{IC}_{50}(\mu \mathrm{mol} / \mathrm{l})$ \\
\hline daedalin A (1) & $28.6 \pm 5.0$ & $48.4 \pm 1.1$ & $61.6 \pm 1.0$ & 208 \\
quercinol (2) & $30.7 \pm 6.7$ & $43.9 \pm 1.2$ & $48.1 \pm 1.7$ & 490 \\
tdaedalin A & $23.7 \pm 5.7$ & $45.5 \pm 3.1$ & $55.6 \pm 1.1$ & 289 \\
\hline
\end{tabular}

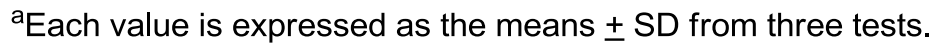


In summary asymmetric syntheses of daedalin A (1) and quercinol (2) was achieved. The tyrosinase inhibitory activity of $\mathbf{2}$ was weaker than that of $\mathbf{1}$ at high concentration. The study of the inhibitory mechanism of $\mathbf{2}$ is currently underway.

\section{Supplementary data}

Supplemental material available: spectroscopic and physical data of $\mathbf{1}$ and $\mathbf{2}$, biological assays. Supplementary data associated with this article can be found, in the online version, at doi:

\section{References and notes}

1. Hearing, V. J.; Jiménez, M. Int. J. Biochem. 1987, 19, 1141-1147.

2. Morimura, K.; Yamazaki, C; Hattori, Y.; Makabe, H.; Kamo, T.; Hirota, M. Biosci. Biotechnol. Biochem. 2007, 71, 2837-2840.

3. Morimura, K.; Hiramatsu, K.; Yamazaki, C.; Hattori, Y.; Makabe, H.; Hirota, M. Biosci. Biotechnol. Biochem. 2009, 73, 627-632.

4. Gebhart, P.; Dornberger, K.; Gollmick, F. A.; Gräfe, U.; Härtl, A.; Görls, H.; Schlegel, B.; Hertweck, C. Bioorg. Med. Chem. Lett. 2007, 17, 2558-2560.

5. Goujon, J. -Y.; Duval, A.; Kirschleger, B. J. Chem. Soc. Perkin Trans. 1 2002, 496-499.

6. Bouzbouz, S.; Goujon, J. -Y.; Deplanne, J.; Kirschleger, B. Eur. J. Org. Chem. 2000, 3223-3228.

7. Kirschleger and co-workers reported that 9 was obtained in $90 \%$ yield using CAN as an oxidant. ${ }^{6}$

8. Kloc, K.; Mlochowski, J.; Syper, L. Chem. Lett. 1980, 725-728.

9. Trost, B. M.; Shen, H. C.; Surivet, J. -P. Angew. Chem. Int. Ed. 2003, 42, 3943-3947. 